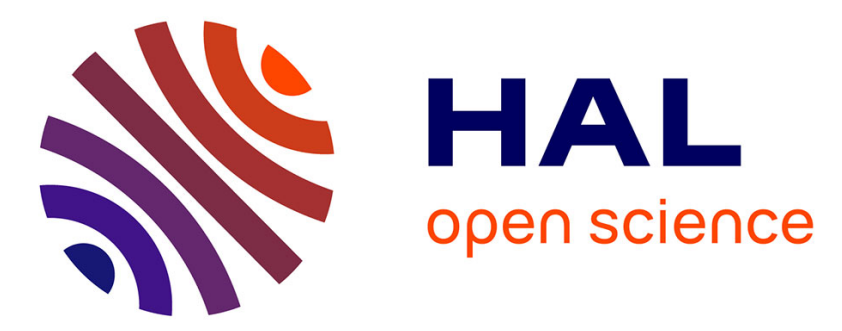

\title{
Modelling and Simulation of the Doctors' Availability in Emergency Department with SIMIO Software. Case of Study: Bichat-Claude Bernard Hospital
}

\author{
Mahmoud Masmoudi, Patrice Leclaire, Vincent Cheutet, Enrique Casalino
}

\section{To cite this version:}

Mahmoud Masmoudi, Patrice Leclaire, Vincent Cheutet, Enrique Casalino. Modelling and Simulation of the Doctors' Availability in Emergency Department with SIMIO Software. Case of Study: Bichat-Claude Bernard Hospital. Mechatronic Systems: Theory and Applications, Springer Verlag (Germany), pp.119-129, 2014, 10.1007/978-3-319-07170-1_12 . hal-01551128

\author{
HAL Id: hal-01551128 \\ https://hal.science/hal-01551128
}

Submitted on 30 Jun 2017

HAL is a multi-disciplinary open access archive for the deposit and dissemination of scientific research documents, whether they are published or not. The documents may come from teaching and research institutions in France or abroad, or from public or private research centers.
L'archive ouverte pluridisciplinaire HAL, est destinée au dépôt et à la diffusion de documents scientifiques de niveau recherche, publiés ou non, émanant des établissements d'enseignement et de recherche français ou étrangers, des laboratoires publics ou privés. 


\title{
Modelling and simulation of the doctors' availability in emergency department with SIMIO Software. Case of study: Bichat-Claude Bernard Hospital
}

\author{
Mahmoud MASMOUDI ${ }^{1}$, Patrice LECLAIRE ${ }^{2}$, Vincent CHEUTET ${ }^{2}$, \\ Enrique CASALINO3
}

\author{
${ }^{1}$ Mechanics, Modelling and Manufacturing Laboratory (LA2MP), Mechanical Engineering \\ Department, National School of Engineers of Sfax (ENIS), BP 1173-3038 Sfax, Tunisia. \\ E-mail: masmoudi.miha@gmail.com \\ ${ }^{2}$ Laboratory of Mechanical Systems and Materials (LISMMA), Higher Institute of Mechanics \\ of Paris (SUPMECA), 3, rue Fernand Hainaut, 93407 Saint-Ouen, France. \\ E-mail: patrice.leclaire@supmeca.fr, vincent.cheutet@supmeca.fr \\ ${ }^{3}$ Emergency Department, Bichat-Claude Bernard Hospital, 46 Rue Henri Huchard, 75018 \\ Paris, France. \\ E-mail: enrique.casalino@bch.aphp.fr
}

\begin{abstract}
Emergency Departments (ED) require an appropriate allocation of human and material resources in order to increase their effectiveness and efficiency and reduce as much as possible the patients' waiting time. This paper describes step by step the patient's stay process at the ED. The SIMIO software was used for the modelling and simulation of this process. This paper also presents a novel method of modelling doctors' availability in the emergency department taking into account their number and availability in trauma and medicine areas. The findings from the different simulated scenarios show that modifying the doctors' number can have a strong effect on the patients' length of stay and the number of exited patients from the service. This work was based on the ED at Bichat Claude Bernard Hospital in Paris, France.
\end{abstract}

Keywords: Modelling, Simulation, Emergency Department, SIMIO software. 


\section{Introduction}

In recent years, applied researchers have become increasingly interested in modelling patients' flow in hospital in order to optimize its services.

The permanent increase of the number of patients who arrive at hospital is one of the factors that make the management of these flows problematic. The random patients' arrival to Emergency Department is its peculiarity compared to other hospital departments. These elements make the control of the patient pathway a difficult task and cause a low anticipation of decision making. The main objective of an emergency department is to ensure patients' support rapidly and qualitatively with an efficient planning of the hospital's resources.

Recent studies have begun to explore various tools and methods in the medical context. Wang et al. (2009) suggested ARIS and Arena to model and simulate an emergency service in Lyon, France. Su et al. (2003) focused on modelling 23 EMS hospitals in Taipei, Taiwan to perform two-tier rescues using computer simulations.

Nevertheless, using the SIMIO software in the context of modelling and simulating patients' flow, taking into account the doctors' availability in the Emergency Department, is as yet an unexplored territory.

The aim of the present paper is to give a suggestion for modelling and evaluating the impact of the change of the doctors' number on the patient's length of stay (LOS).

The remainder of this paper is divided into three sections. Section 2 describes the patient's stay process: the steps and actions made by the patient from his ED entry to exiting in a chronological order. Section 3 provides details about modelling Bichat ED, the considered hypotheses and the different used modelling concepts. The last section is an evaluation of the variation of the physicians' number who are present at the ED.

\section{The patient stay process}

Every year, more than 72.000 patients visit the Bichat emergency department; this number is increasing from one year to another. This emergency department receives an average of 190 patients per day with a variable inter arrival time.

The patient stay process includes many steps: Patients' arrival, Admission and registration, Waiting, Triage, Consultation, Additional analyses and Exit (see Fig. $1)$. 


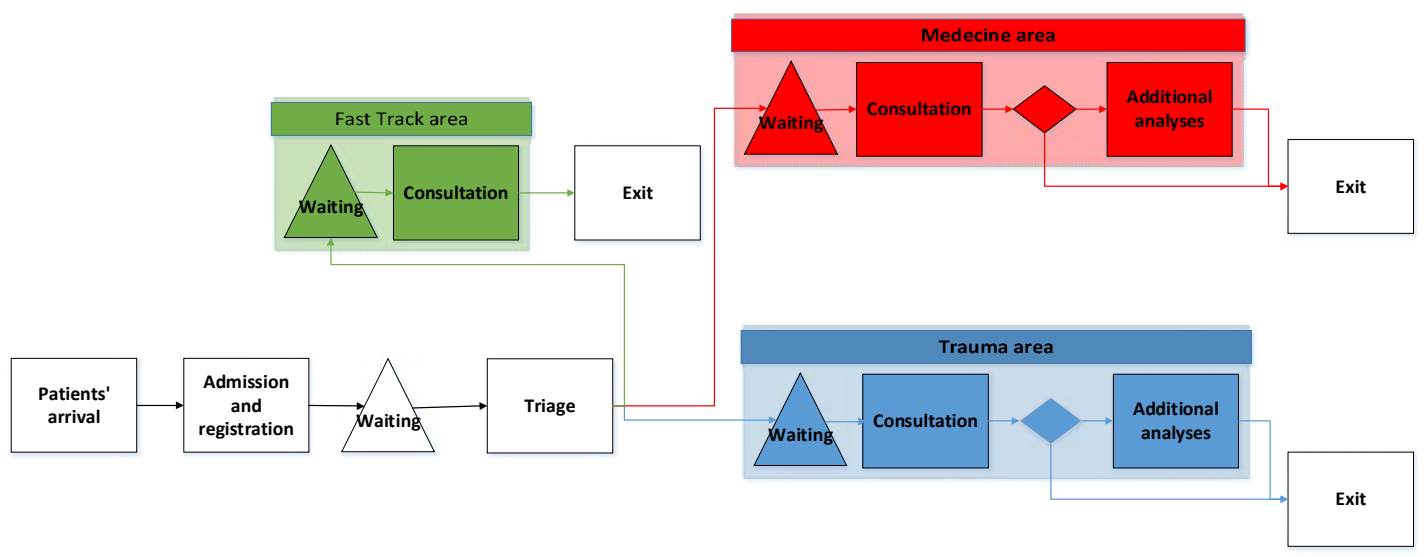

Fig. 2 Patient stay process

Patients can access to the ED by either one of the two possible gates depending on their arrival mode: personal vehicle or ambulance.

As soon as they arrive to the ED, either standing or in lying position, they go to the reception. A nurse is installed there to admit and register patients. She asks them about their identity and social security number and checks whether they already benefited from the hospital's services.

Generally, the first arrived patient is the first served (FIFO) with some exceptions, such as giving priority to lying patient in a serious condition.

After the admission of the patient by a nurse, the patient is installed in one of the waiting rooms: sitting waiting room or lying waiting room. This assignment is done according to the patient's condition: standing or lying.

Then two triage nurses (TN) when available, move from their boxes to the reception to retrieve the next patient's medical chart. Each patient is installed in a triage box and asked about his medical history (earlier diseases, surgeries, allergies, current treatment, etc.) and to help the triage nurse to identify his health condition. TN decides subsequently to which area the patient should be oriented. According to the pathology type, three choices are possible:

Fast Track area.

Trauma area (or blue area).

Medicine area (or red area)

The pathology type is rated from 1 to 5 according to this scale of cases gravity:

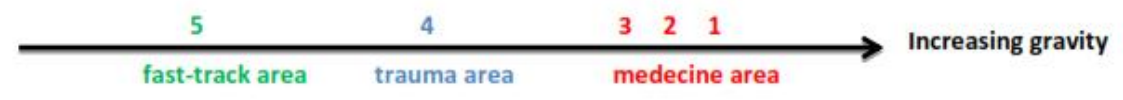

At the end of triage, the nurse installs the patient in the waiting room and returns to the reception to take care of another patient.

Patients with gravity level 5 return to the reception waiting area and wait to the consultation of a Fast Track doctor. Generally, these patients leave the Emergency Department quickly. 
A part of standing and lying patients are oriented towards the trauma area before waiting for the doctor consultation in the trauma waiting room. A nurse is responsible for installing them in the trauma boxes. Two doctors are placed into the blue area to support patients and take one of the following three decisions:

- If patients have no trauma problems and need treatments or additional analyses, they are therefore allowed to leave the emergency service.

- If patients have trauma problems and do not need further analysis, they are in this case supported by a nurse in their boxes to be treated. After treatment, patients are allowed to leave the service.

- If patients have trauma problems and are in need of additional analysis, they go to the radiology department then return to settle in the plastering box. Plastering requires the availability of a box and a doctor simultaneously. After plastering, these patients leave the ED.

The remainder of the patients are directed towards one of the two holding areas in the medicine area:

- A sitting room with infinite capacity for patients who are not in a critical state and can sit.

- A lying waiting room for lying patients.

When a medicine box is available, the first arrived patient in one of the waiting rooms is installed into before being consulted by a red area's doctor. They examine the patient and prescribe the medical review or the additional analyses needed, then take one of the following three decisions:

- The patients who were lying and then standing up and the standing patients who do not require any additional analyses are sent to the seating waiting room (6 places) where they await the results of the balance sheet. Then, after receiving treatment from the doctor, they leave the Emergency Department.

- Recumbent patients who do not require any additional analyses are sent to the lying waiting room (6 places) where they await the results of the medical review and stay under nurses' observation. Following the treatment of their medical condition by a doctor, they are transferred to the hospital or to "the door service" to be hospitalized. (The door service is an area that is located next to the emergency department that hosts hospitalized patients or transferred to other hospitals).

- Patients (standing or lying) who need further analysis, leave the medicine box to do their analyses then settled back in one of the mentioned above waiting rooms:

- Sitting Waiting room to treat their disease if they have to leave the service.

- Lying Waiting room to put them under observation before hospitalization. 
Modelling and simulation of the doctors' availability in emergency department with SIMIO

Software. Case of study: Bichat-Claude Bernard Hospital

\section{Modelling doctors' availability with SIMIO}

At the ED, an emergency doctor (internal or senior) must treat and admit patients whose state of health necessitates a quick and fast support at any time of day or night. They examine the patient and make a diagnosis in a little time. That is why we find a dynamic number of physicians in Bichat hospital ED depending on time.

Below Table 1 is a summary of the number of physicians on duty in the emergency service for each day of the week and each time slice of the day during the period of investigation.

Table 1. Doctors number in the emergency department.

\begin{tabular}{lcccc}
\hline Day/ Time & [8:30 AM - 2:00 PM] & [2:00 PM - 6:30 PM] & [6:30 PM - 12:00 PM] [0:00 AM - 8:30 AM] \\
\hline $\begin{array}{l}\text { From Monday to } \\
\text { Saturday }\end{array}$ & 8 & 9 & 6 & 4 \\
Sunday & 4 & 6 & 6 & 4 \\
\hline
\end{tabular}

The availability of the physician is not always equal to $100 \%$ of their working time. In fact, the Fast track physician is able to treat 4 patients per hour, while a medicine or trauma doctor can process 1.6 patients per hour.

This is due to the complexity of their tasks; they consult patients, complete administrative tasks, review the additional analyses results and research on the patient disease before making their medical decision. We can classify these tasks into three types, each representing $1 / 3$ of their availability in the ED.

The first part presents the patient first contact and consultation in his ther box, the second corresponds to reflection and decision-making time. The rest contains displacements inside the Emergency Department, breaks, and entering the data into the hospital information system.

To model the last $1 / 3$, it was assumed that the doctor makes a break of 15 minutes every 45 minutes. And to randomize these events, we assigned the duration of the break to a uniform distribution with parameters $(\mathrm{min}=10 \mathrm{~min}, \max =$ $20 \mathrm{~min}$ ) and the inter arrival of breaks to a uniform distribution with parameters $(\min =40 \mathrm{~min}, \max =50 \mathrm{~min})$.

\subsection{Modelling the blue area doctors}

For modelling the availability of blue area doctors, we adopted the following hypotheses:

A blue doctor means a physician assigned to blue area.

2 blue doctors are present at the Emergency Department 24 hours a day and 7 days a week. 
If there is one patient in the blue box and two doctors are available, the 1st doctor supports the patient.

The second physician is the only responsible for the plastering. To model this in SIMIO, we used 2 support servers: "consultation_doctor_b1" and "consultation_doctor_b2" followed by two decision servers «decision_doctor_b1» and «decision_doctor_b2»(see Fig. 3).

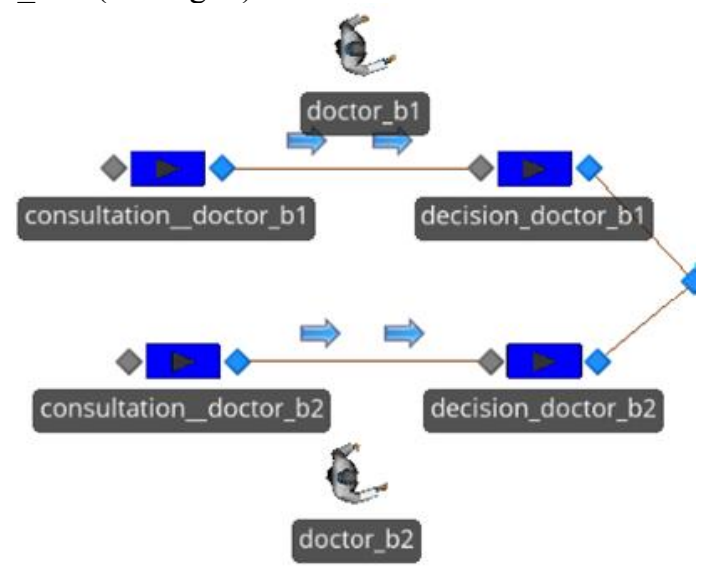

Fig. 3 Modelling blue area's doctors

Each of these servers is characterized by a fixed capacity equal to 1 , a processing time equals 15 minutes, a blue doctor as a secondary resource and the ranking rule "FIFO".

In order to model the remaining time of the doctor, we created for each of the two blue doctors a subsystem (see Fig. 4). This subsystem is composed of a chips source that randomly creates one by one with a time of inter arrival following a uniform law with parameters ( $\min =40 \mathrm{~min}$., $\max =50 \mathrm{~min}$.). Then these chips move to a server called "pause doctor $b$ " where they await for the passage of the "doctor b". The duration of the pause also follows a uniform law with the parameters $(\min =10 \min ., \max =20 \mathrm{~min}$.). Finally, the chips that were created exit through "sink_b".

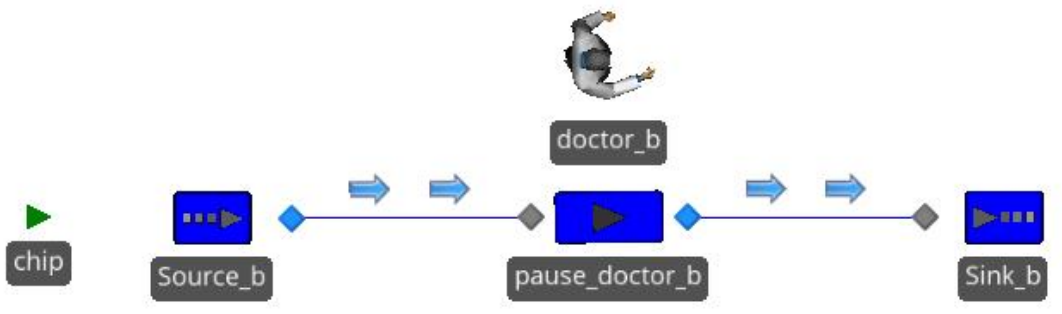

Fig. 4 Modelling a blue doctor break 
Modelling and simulation of the doctors' availability in emergency department with SIMIO Software. Case of study: Bichat-Claude Bernard Hospital

To validate this model, we tested it for a blue doctor who is available $24 \times 7$ hours. After a full day simulation, it was found as results:

The number of patients entered and came out of the consultation doctor b1' server are both equal to 33 patients/day. So, we can say that the doctor consulted 33 patients in their blue boxes.

The number of patients entered and came out of the server 'decision_doctor_b1' are equal to 33 patients per day and 32 patients/day respectively; which means that the doctor consulted 33 patients but there is still a patient waiting in his box without decision.

\subsection{Modelling the red area doctors}

The availability of doctors in the red area is different from the blue one because it has a variable number of physicians during the day.

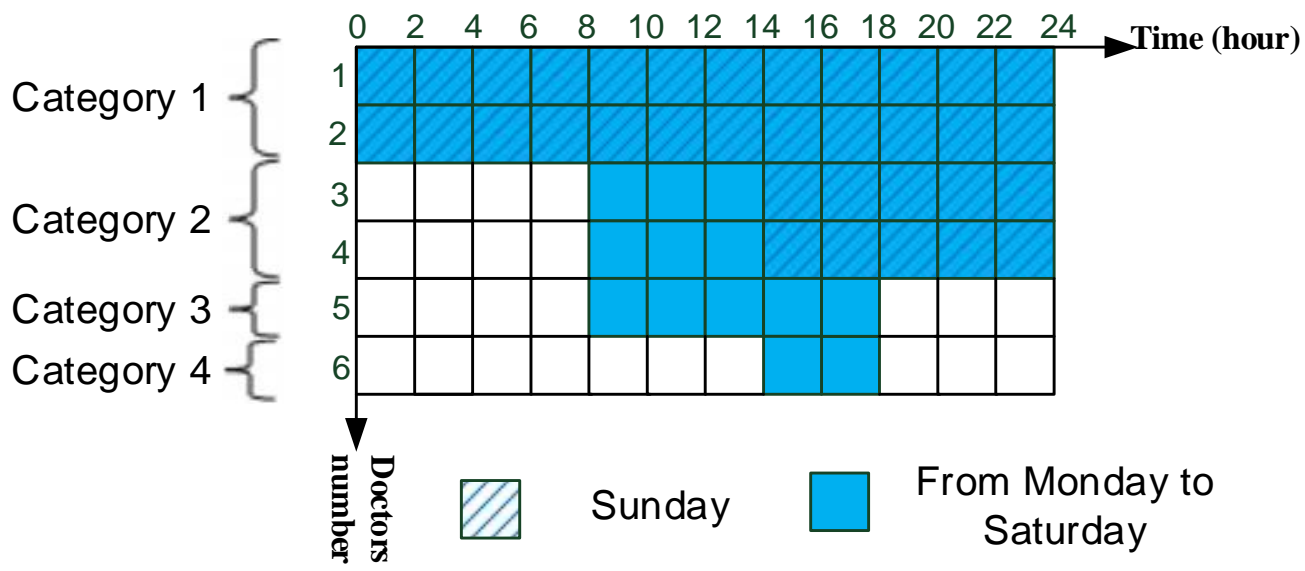

Fig. 5 Blue area doctors planning

In Fig. 5, the hatched blue color represents the doctors' availability on Sunday and the blue color for the other days. To model this constraint, we classified the doctors into 4 categories.

For that, we created 5 day patterns, indicating the start time and the end time of service for each category and 4 work schedules under SIMIO software.

Each day pattern presents a planning schedule for one day (Fig. 6). And each work schedule (Fig. 7) is a weekly planning, setting for each day the matching day patterns. 


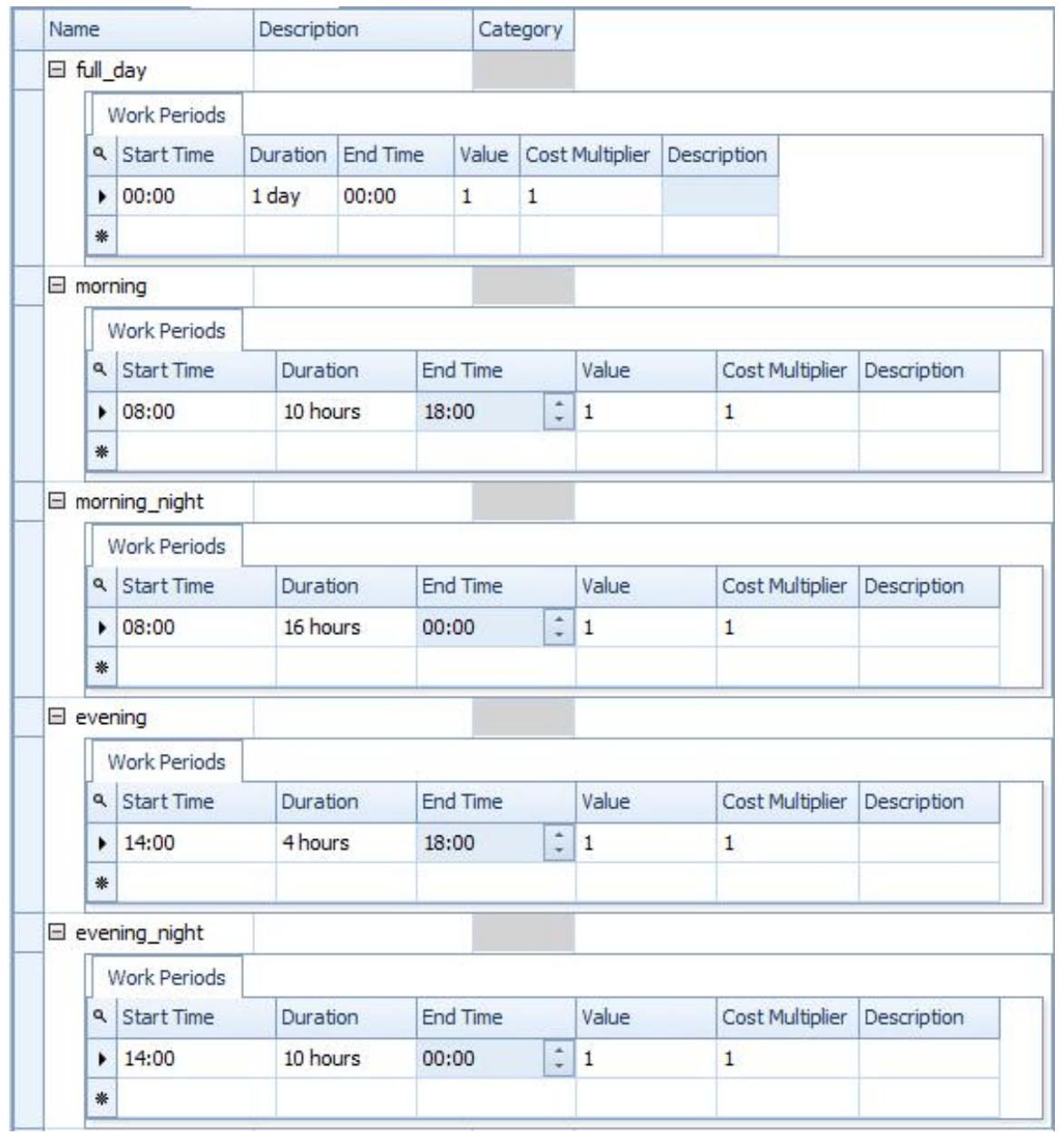

Fig. 6 Day patterns definition in SIMIO software

\begin{tabular}{|c|c|c|c|c|c|c|c|c|c|c|}
\hline Name & Start Date & Descript... & \begin{tabular}{l|l} 
Days & $\ldots$ \\
\end{tabular} & Saturday & Sunday & Monday & Tuesday & Wednesday & Thursday & Friday \\
\hline 田 category 1 & $01 / 01 / 2011$ & $24 \mathrm{~h} / 24 \mathrm{~h}$ & 7 & full_day & full_day & full_day & full_day & full_day & full_day & full_day \\
\hline 田 category 2 & $01 / 01 / 2011$ & $16 \mathrm{~h} / 10 \mathrm{~h}$ & 7 & morning_night & evening_night & morning_night & morning_night & morning_night & morning_ni... & morning_night \\
\hline ⿴囗十 category 3 & $01 / 01 / 2011$ & $10 \mathrm{~h} / 24 \mathrm{~h}$ & 7 & morning & & morning & morning & morning & morning & morning \\
\hline 田 category4 & $01 / 01 / 2011$ & $4 h / 24 h$ & 7 & evening & & evening & evening & evening & evening & evening \\
\hline
\end{tabular}

Fig. 7. Work schedules definition in SIMIO software

Then, the same modelling approach as for blue doctors was adapted for the red sector physicians. A red subsystem was created to model the availability of the doctors. The hypothesis that were used are as follows: 
Modelling and simulation of the doctors' availability in emergency department with SIMIO Software. Case of study: Bichat-Claude Bernard Hospital

- The existence of 2 red doctors present 24 hours a day and 7 days a week at the emergency service.

- When a patient is in a red box and several red doctors are available, it is the doctor who has the greatest priority value that supports the patient (doctor $r 1$ has the first priority and doctor_r6 has the least one).

Under SIMIO, 6 support servers "consultation_doctor_r" were used and followed by other six decision servers "dec_doctor_r" (see Fig. 8). Each of these servers is characterized by a fixed capacity equal to 1 , a service time "processing time" equal 15 minutes, a red doctor as a secondary resource and FIFO "Ranking Rule".

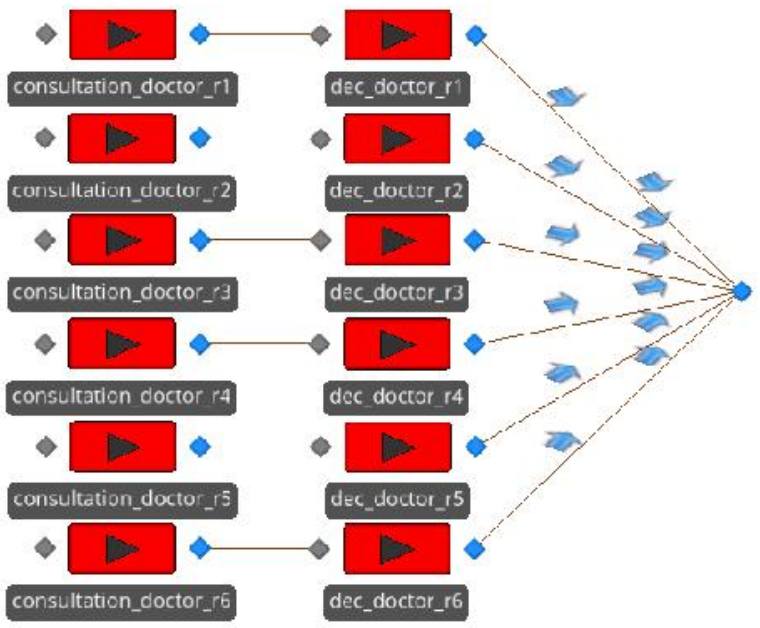

Fig. 8. Modelling red area's doctors

To model the red doctors availability, this subsystem is composed of source that randomly creates chips one by one with a time of inter arrival following a uniform law of parameters $(\min =40 \mathrm{~min}, \max =50 \mathrm{~min})$. Then these tokens go through a server called "pause doctor $r$ " where they await the passage of the "doctor_r". The duration of the pause follows a uniform law with parameters (min $=10 \min ., \max =20 \min$.). Finally, chips exit through "sink_r".

In creating these chips for 24 hours of simulation, we may exceed $33 \%$ of the availability of a doctor belonging to certain categories which do not cover all of the 24 hours. For this, we need to destroy some of them. These extra chips are rejected out from the beginning to the exit "sink1". This path is provided for the chips arriving when the doctor is not available in these periods of times (see Fig. 9). 


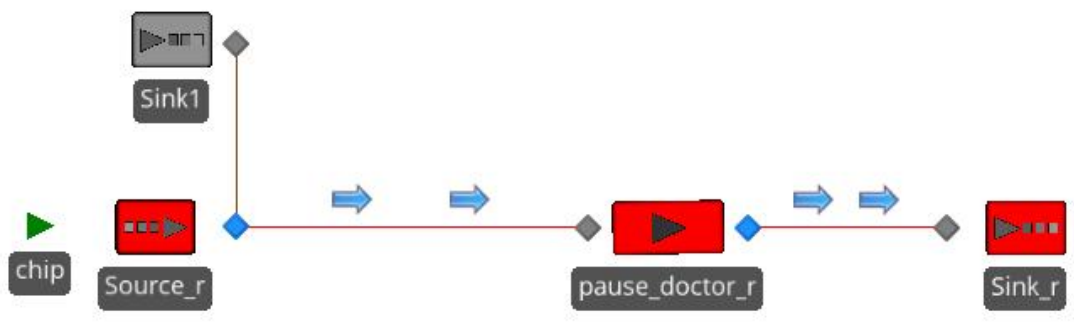

Fig. 9 Modelling a medicine doctor break

After simulation (of one week), we found a coincidence of the simulation results with reality observed situation of the ED; the doctor works during his schedule of work, his time is divided as follows: $1 / 3$ for the consultation of patients, $1 / 3$ for decision-making and the rest for breaks. So we can validate our model.

\section{Variation in the number of doctors}

The emergency physicians wanted to know the influence of the increase and decrease of the number of doctors in the emergency on the LOS. We conducted several simulation replications to ensure the reliability of gathered statistical data.

This experiment consists of varying the number of doctors belonging to the first category; who are always present in the red area for two days of simulation. Five scenarios were created (see Table 2).

Table 2 Red area physician's number change

\begin{tabular}{cccc}
\hline Scenario $\mathbf{N}^{\circ}$ & Number of replications & Number_doctor_r1 & Number_doctor_r2 \\
\hline 1 & 100 & 1 & 1 \\
2 & 100 & 2 & 1 \\
3 & 100 & 1 & 2 \\
4 & 100 & 2 & 2 \\
5 & 100 & 3 & 3 \\
\hline
\end{tabular}

The variable 'number doctor $\mathrm{rl}$ ' refers to the first doctor of category 1 in the red area. If this value is equal to 2 , it means that the number of doctors is multiplied by two. Similarly, the variable "number_doctor_r2" presents the second doctor in the first category in the red zone. For example, the first scenario shows our basic model (compliant with reality: doctor_r1 + doctor_r2) and the second scenario is to add a third red doctor who shall share with the "doctor_r1" their medical and administrative tasks. 
Modelling and simulation of the doctors' availability in emergency department with SIMIO Software. Case of study: Bichat-Claude Bernard Hospital

After 100 replications of these various scenarios, we obtained the results presented in Table 3.

Table 3. Simulation results

\begin{tabular}{ccc}
\hline Scenario $\mathbf{N}^{\circ}$ & LOS average & Exited patients number \\
\hline 1 & 413,769 & 128,9 \\
2 & 354,422 & 148,9 \\
3 & 370,946 & 145,7 \\
4 & 332,359 & 152,3 \\
5 & 315,401 & 156 \\
\hline
\end{tabular}

From these results, we note that the addition of a doctor leads to decrease of the LOS average time of a patient's case gravity 1,2 or 3 and also to increase the number of patients exited from the ED.

In addition, from the discrepancy of results between the second and the third scenarios, we can say that the addition of a doctor $\mathrm{r} 1$ is more advantageous than the addition of a doctor $\mathrm{r} 2$.

\section{Conclusion}

We developed with SIMIO software an Emergency department model and used it to test several scenarios by simulation, changing one of its parameters each time. The main idea of this paper is to suggest a way to model the doctors in the emergency department taking into account their availability constraints in order to get more precise results conforming to the real values.

Further short-term work will focus on issues of integrating the model into a tool for decision support for optimization problems such as the medical resource allocation. Another issue is to check the influence of the increase in the number of patients arriving at the emergency department in the coming years and to develop a methodology to account for the optimum number of doctors that the ED should have.

\section{Acknowledgements}

The authors acknowledge the precious collaboration of the emergency department in Bichat-Claude-Bernard Hospital; we would like to thank all the staff, and particularly Pr. CASALINO Enrique, Emergency Department Director, for their time and effort contributed to the present research work. The authors also grateful- 
ly acknowledge the helpful comments and suggestions of the reviewers, which have improved the presentation.

\section{References}

SIMIO. (2007). Simio, process flow simulation software 2D/3D, Net Prints. http://www.simio-simulation.fr/ Accessed11 Mars 2013

Tao Wang, Alain Guinet, Aissam Belaidi, Beatrix Besombes, (2009), Modelling and simulation of emergency services with ARIS and Arena. Case study: the emergency department of Saint Joseph and Saint Luc Hospital, Production Planning \& Control,Vol. 20, No. 6, September 2009, 484-495

Shamsuddin Ahmed, Francis Amagoh (2008), Modelling Hospital Resources with Process Oriented Simulation, Volume I, No. 1, 2008, Central Asia Business, ISSN 1991-0002.

Syi Su, Chung-Liang Shih, (2003), Modelling an emergency medical services system using computer simulation, International Journal of Medical Informatics (2003) 72, 57-72.

JLASSI, J. (2011). Amélioration de la performance par la modélisation des flux logistiques des patients dans un service d'urgence hospitalier.

AUGUSTO, V. (2008). Modélisation, analyse et pilotage de flux en milieu hospitalier. Saint-Etienne.

McGuire, F., (1994). Using simulation to reduce length of stay in emergency departments. In: J.D. Tew et al., eds. Proceedings of the 1994 winter simulation conference, IEEE, Orlando, FL, 861-867. 